\title{
Undergraduate optical design courses at the Rose-Hulman Institute of Technology
}

\section{Zoran Milanovic, Robert Bunch, Galen Duree}

Zoran Milanovic, Robert M. Bunch, Galen C. Duree, "Undergraduate optical design courses at the Rose-Hulman Institute of Technology," Proc. SPIE 9663, Eighth International Topical Meeting on Education and Training in Optics and Photonics, 96632J (6 October 2003); doi: 10.1117/12.2208496

SDIE Event: Eighth International Topical Meeting on Education and Training in Optics and Photonics, 2003, Tucson, Arizona, United States 


\title{
Undergraduate optical design courses at the Rose-Hulman Institute of Technology
}

\author{
Zoran Milanovic, Robert M. Bunch, and Galen C. Duree \\ Rose-Hulman Institute of Technology, 5500 Wabash Avenue, Terre Haute, IN 47803 \\ telephone: 812-877-8968; fax: 812-877-8023; e-mail: milanovi@rose-hulman.edu
}

\begin{abstract}
Three optical design courses are taught at the junior-senior undergraduate level at RoseHulman Institute of Technology. This paper will discuss a lens design course which utilizes complimentary keys to Code V provided by ORA and two design courses in which students work on projects motivated by commercial industry.

(C)2003 Optical Society of America
\end{abstract}

OCIS codes: (220.3620) Lens design; (220.2740) Geometrical optics, optical design

\section{Summary}

The Optical Engineering degree curriculum at Rose-Hulman contains three optical design courses for undergraduate majors. The first course, Lens Design and Aberrations, is taught to junior and senior optical engineering students who have completed the prerequisite course in paraxial optics. The first half of the course is spent reviewing firstorder ray tracing and introducing the third-order aberrations and their effects upon imaging. The second half of the course is a series of weekly lens design assignments that start with achromats, proceed through landscape lenses and triplets, introduce mirror and catadioptric systems and finish with a tolerancing exercise. Emphasis is placed upon understanding and satisfying system requirements and utilizing standard methods of performance evaluation such as spot diagrams, ray intercept plots, and MTF graphs. The tolerancing exercise includes a Request for Quote memo with supporting documentation to demonstrate how the designer would communicate with the manufacturer. The aspect of this class that differs from lens design courses of past years is the availability of Code $\mathrm{V}^{1}$ keys for use by the students during the course. Through an agreement between ORA and Rose-Hulman, the students are provided with Code V design software that they can load into their (college-required) personal laptops. This gives the students the flexibility of working on their designs at any convenient time rather than being forced to compete with each other for time on a single computer that contains the software.

The second and third courses are Optical Engineering Design I (for juniors) and Optical Engineering Design II (for seniors) which are taught concurrently. In these courses, the students are organized into project teams and assigned projects defined by Statements of Work. These Statements of Work are solicited from commercial companies or research groups by the class instructors before the beginning of the class. The students are required to submit Responses to their Statements and set up work schedules with milestone deadlines. Then the students must design their project optical system, build and test a prototype system, demonstrate the system and submit a final report at the end of the course. During the course, the students give weekly progress reports to the class instructors. Grading is based upon the progress reports, meeting deadlines, the final demonstration, the final report and a final oral examination.

\section{References}

1. Code V is distributed by Optical Research Associates, Pasadena, California. 